\title{
SELFIES DE VÍTIMAS: IMAGEM E AUTENTICIDADE EM POSTAGENS DE REDES SOCIAIS
}

\author{
Angie Gomes Biondi
}

\begin{abstract}
RESUMO
Este texto procura refletir sobre a exposição crescente que o autorretrato, nomeadamente, as selfies, de pessoas que se enunciam vítimas têm adquirido em sites de redes sociais. As vítimas de violência se declaram e se apresentam em fotografias que expõem situações marcadas pela dor e sofrimento. Pensadas como gesto que configura uma forma de relato de si, estes materiais indicam os aspectos que participam do processo de visibilidade no contexto on-line. Deste modo, dois pontos se destacam no exame deste material: a) funcionam como recurso à afirmação da autenticidade como um dos índices culturais da moral que define o que seria aceitável à declaração daquele que se diz vítima; b) promovem formas de interação afetiva com os demais usuários. O exercício de análise privilegia exemplares recentes veiculados através de uma hashtag de campanha, pelo Instagram.
\end{abstract}

\section{Palavras-chave}

Autenticidade; imagem; redes sociais; vítima

\begin{abstract}
The purpose of the article is to reflect on the growing exposure of self-portraits, more commonly known as selfies, of people presented as victims in the social network sites. Victims of violence declare and present themselves in photographs that expose situations of pain and suffering. Designed as a gesture that represents a form of self-reporting, it indicates certain aspects of the online process of visibility. Therefore, our analysis indicates two standing out points a) the selfie is a kind of resource for the affirmation of authenticity, as a cultural indicator of morality that defines acceptance of declaration of the one who calls himself a victim; b) it promotes forms of affective interaction with other users. Our analysis favors recent examples that have been distributed through a hashtag campaign on Instagram.
\end{abstract}

\section{KEYWORDS}

Authenticity; image; social networks; victim

\section{INTRODUÇÃO}

Conforme as definições mais atualizadas, sites de redes sociais, como Twitter, Facebook, Instagram, entre outros, atuam como redes na medida em que estes recursos ampliaram atividades que vão além do foco no perfil do usuário e passaram a integrar fluxos de conteúdo que podem ser atualizados com a possibilidade dos próprios usuários produzirem, compartilharem, consumirem e estabelecerem conexões publicamente (Recuero, Bastos \& Zago, 2015). Estes espaços funcionam como plataformas de 
comunicação nas quais a experiência dos sujeitos é variável conforme a rede construída e os conteúdos compartilhados. Este aspecto de construção traz uma diferença considerável quando se observa redes sociais online como metáforas dos agrupamentos offline, que não se efetivam da mesma forma, mas que em sua especificidade pode oferecer indicativos importantes sobre o que ganha destaque ou o que desaparece neste novo ecossistema informático.

Ao menos duas características são importantes nesta observação ao contexto de redes. A primeira se refere aos rastros deixados pelos sujeitos usuários (contatos, trocas, conversações, mensagens), que permanecem e podem ser recuperados e buscados, e a segunda se refere às representações que se constituem e se mantêm ativas, ou não, conforme as diversas ações dos sujeitos, a partir dos recursos que as próprias redes oferecem. "No espaço online, essas redes sociais são demarcadas não somente pelos rastros deixados pelos atores sociais e pelas suas produções, mas também por suas representações" (Recuero et al., 2015, p. 23). Assim, a participação do sujeito é ampliada conforme as possibilidades de produção e intervenção de conteúdo, bem como suas conexões se tornam publicizadas pelos próprios sites formando representações que podem ser mais evidentes e mais visíveis em um caso que em outro. Contudo, isso não quer dizer que haja uma ampliação igualitária dos conteúdos, ao contrário.

Neste contexto competitivo, as postagens de vítimas, sobretudo aquelas marcadas pela violência sexual e de gênero, têm ganhado relevância entre os usuários destas plataformas, a ponto de serem reproduzidas e apropriadas por diversos veículos de comunicação e imprensa que anseiam por novas pautas. É possível encontrar as repercussões destes inúmeros casos postados em programas de Tv, rádio, jornais, portais de notícias, entre outros, como se a vida comum exibida nas redes sociais tivesse alcançado apelo suficiente e legitimidade proveniente de seu teor testemunhal para mobilizar o interesse de diversos públicos e para os mais diversos fins. Assim, esta recursividade entre mídia se mostra um aspecto relevante nesta recomposição dos lugares de falas dos sujeitos na sociedade atual trazidos, principalmente, pela produção e compartilhamento de diversas histórias pessoais em sites de redes sociais.

Neste turbilhão informativo de compartilhamentos e replicações das situações de violências alguns posts se destacam na forma de relatos pessoais, autobiográficos, nos quais a declaração pessoal ganha uma posição privilegiada pelos sujeitos que se enunciam e que não buscam apenas registrar as infelicidades vividas, mas afirmar-se perante o olhar público através destas produções compartilhadas online. Precisamente, nos interessa o aspecto seletivo que há na exposição deste sujeito que se declara e se mostra buscando afirmar sua condição de vítima através de autorretratos como uma forma de atestação pessoal legítima e autêntica. Dentre os diversos casos disponíveis nas redes, a investigação observou as imagens veiculadas pela hashtag \#creatingconsentculture, através do Instagram, entre 2015 e 2016, como exemplar de uma campanha internacional contra violência sexual e de gênero. Este texto apresenta alguns dos exemplares trabalhados na pesquisa. 


\section{A DEClARAÇÃo PESSOAL da VÍtima NOS DESLOCAMENTOS MORAIS DA AUTENTICIDAdE}

Para além das grandes explicações acerca dos indicativos históricos e culturais de uma sociedade que seria marcada pelos condicionantes tecnológicos, ou seja, antes da imediata justificativa de que se trata apenas de uma característica da contemporaneidade tecnológica que associa o "mundo da vida" e a natureza midiática, este texto procura aprofundar esta discussão através da observação direta dos materiais que circulam cotidianamente. Inicialmente, indica-se que as articulações de poder em jogo neste tipo de contexto sociotécnico manejam processos de sociabilidade nos quais se configuram a produção, a partilha e a circulação de materiais pessoais e de histórias da vida comuns pautadas por valores morais e políticos em um nível mais complexo desta relação entre sujeitos e instrumentos comunicacionais e tecnológicos.

A partir deste contexto peculiar, como pensar os sites de redes sociais como espaços de conversações que tem adquirido certa relevância no espaço público? E, em que medida pode-se considerar seus materiais postados, no caso em questão, as fotografias produzidas e partilhadas pelas próprias vítimas como referenciais privilegiados de uma experiência originária de dor e sofrimento? Quais critérios definem sua repercussão e legitimidade neste contexto fluido e constantemente modificado? Para compreender estas questões é preciso ressaltar que uma característica cultural importante se coloca nos modos de enunciação da vítima neste contexto de redes. Se no período moderno o sujeito que vivenciava uma dor ou sofrimento precisava ser inscrito em uma condição de vulnerabilidade através de uma designação normativa e exterior legitimada por discursos conferidos pelas instâncias políticas, religiosas, entre outros, pelos "conjuntos ritualizados dos discursos", como indicou Foucault (2001), agora ele mesmo antecipa sua condição de vítima e se enuncia a partir dos recursos comunicacionais disponíveis em seu cotidiano.

Esta forma de declaração e exposição de si, no entanto, como apropriação do espaço de fala pelo sujeito comum encontra também limites, tensões e conflitos que não são provenientes de um manejo exclusivamente tecnológico, mas repercussão de um quadro sociocultural no qual atuam. Um dos aspectos observados é a legitimidade que se atribui a estes materiais como uma forma de declaração pessoal de sua condição de vítima. Deste modo, o estudo indicou a necessidade de revisar a discussão da passagem da sinceridade à autenticidade como aspectos morais variáveis conforme o conjunto de referenciais vigentes na sociedade moderna.

Neste percurso teórico e reflexivo Lionel Trilling (2014) examinou os ideais cognatos da sinceridade e autenticidade como dois princípios fundamentais para a formação e aceitação social do sujeito. O autor iniciou seu percurso argumentativo questionando quais valores modelam e animam a vida moral em determinadas épocas. Para ele, conforme a época, alguns valores perduram, mas outros mudam e são substituídos rapidamente conforme o fluxo incessante das coisas que marca o modo social do ser contemporâneo. Segundo o autor, esse reconhecimento das transformações da vida moral é destacado há tempos pela literatura, mas também pelo pensamento e pela ciência, que mostram o quanto a "vida moral é condicionada por uma cultura específica" (Trilling, 
2014 , p. 12) embora a natureza humana pareça, a seu modo, perene, animada por paixões consideradas universais.

Ao observar mais atentamente os fenômenos da vida cotidiana é que se pode notar os detalhes da crença, do pensamento e do comportamento que distinguem a moral de determinada época da moral de outra. A partir da observação dos materiais que compõem o cotidiano das pessoas, Trilling (2014) destacou que, historicamente e culturalmente, a vida moral da Europa, no período moderno, acrescentou a si mesma a sinceridade como um novo elemento ou nova qualidade do "eu". Segundo ele, este percurso moral da sinceridade ao longo do tempo modelou, de certa maneira, o modo como é concebida ainda hoje, ou seja, compreendida como a congruência entre uma declaração pessoal e o sentimento real daquilo que se declara:

se o homem sincero é aquele que evita ser falso sendo verdadeiro consigo mesmo, temos que esse estado de existência pessoal não deve ser conquistado sem um intenso esforço. Não obstante, em certo momento da história alguns homens e classes de homens passaram a conferir a tal esforço suprema importância na vida moral, desse modo, por cerca de quatrocentos anos, o valor atribuído à iniciativa da sinceridade tornou-se um traço saliente, talvez até definidor, da cultura ocidental. (Trilling, 2014, p. 16)

Conforme sua observação, a produção literária foi um campo que teve de lidar com estas questões desde cedo, pois este aspecto comparecia nas discussões sobre a legitimidade de sua prática produtiva. O escritor ou o poeta, por exemplo, não eram considerados uma pessoa, mas uma persona, uma espécie de existência exclusivamente estética de acordo com o protocolo literário vigente da época. Segundo Trilling (2014), nas duas últimas décadas do século XX é que os poetas ingleses e norte-americanos esvaziaram pragmaticamente esta doutrina sagrada da persona e modificaram os valores de sinceridade no campo literário, e por extensão, cultural e também social.

Em paralelo, na vida cotidiana essa ambivalência ainda se apresenta, porém de modo naturalizado. Quando se menciona o papel profissional de alguém, o papel de mãe ou o papel de mulher, entre outros, o que se designa ainda é esta diferença moral que definia os sujeitos conforme uma categoria social e segundo o desempenho de uma função na sociedade que caracterizou todo o período moderno; como se, por baixo de todas estas camadas, houvesse um original e verdadeiro eu oculto da sociedade.

É aqui que reside o nó górdio da sinceridade como vontade e realidade congruentes. Em seus estudos, Trilling (2014) observou que a possibilidade de permanência desta associação direta deixou de ser aceitável e passou a ser questionada quando a sociedade moderna atribuiu um valor moral à aparência de ser aquilo que se dizia ser, ou seja, trouxe a imagem como elemento de constituição decisivo à palavra declarada e, por extensão, qualificou o olhar público como outro critério de avaliação, a partir do qual se impõe outros modos de credibilidade para as declarações pessoais. Para o autor, a suspeição marcou a autenticidade como uma exigência e um novo critério que afirmava, ou não, a pretensa declaração pessoal como sincera: 
sob as exigências do critério de autenticidade, muito do que outrora se acreditava formar o tecido da cultura passou a parecer de pouco valor, uma mera fantasia ou rito, uma manifesta falsificação. Todavia, antes de a autenticidade surgir para insinuar as deficiências da sinceridade e usurpar seu lugar em nossa estima, a sinceridade reinou no firmamento cultural e dominou as ideias de como os homens deveriam ser. (Trilling, 2014, p. 23)

No campo das produções literárias e escritos de si, a autobiografia já estava consolidada na Europa, desde o século XVI, como uma espécie de escrita adotada principalmente pelos protestantes que relatavam suas experiências pessoais religiosas. Essa forma de escrita se revestia de uma boa fé sobre a palavra do homem comum entendida como uma revelação pessoal de sua experiência com o divino e a espiritualidade.

O sujeito da autobiografia, a partir deste contexto histórico, não era nada mais que um eu determinado a revelar-se na plenitude de sua verdade, a demonstrar, pela palavra dada, que era sincero. Esta atitude reveladora se apresentava com uma força declarativa inquestionável e por isso deveria ser considerada fonte de admiração e confiança, na medida em que a sinceridade predominava como valor moral.

Porém, o século XX faz declinar a sinceridade em prol da necessidade de critérios, sobretudo, jurídicos, que passam a validar as declarações pessoais. Daí em diante, outros aspectos viriam modelar a autenticidade como um valor social para qualquer produção dos sujeitos fazendo declinar a sinceridade como manifestação da verdade direta e, em boa medida, ética.

É nesta relação conflituosa entre sinceridade e autenticidade que Trilling (2014) indica um maior estado de tensão na afirmação das declarações pessoais como sinceras, pois a exigência de autenticidade ultrapassa a sinceridade como valor volitivo e legítimo para atuar agora no campo do reconhecimento social. A partir daí toda produção pessoal precisaria se afirmar não pela declaração apenas, mas pela moralidade vigente de uma época que se transforma e institui novos critérios pautados pela autenticidade, pelo ato de tornar autêntico.

A moralidade, segundo Charles Taylor (1997), é um campo de valores estabelecido coletivamente e historicamente variável. Ela é uma espécie de quadro tácito de referências e ideais que confere sentido às decisões e ações dos indivíduos em relação ao outro e a si mesmo. A moralidade não é um conjunto de códigos fixos que coordenam exteriormente as ações dos indivíduos, mas um referencial que anima condutas e orienta os sujeitos a partir de noções e concepções valorizadas em um determinado período da sociedade. No cotejo destas leituras é possível observar que sinceridade e autenticidade atuam como dois grandes índices históricos e culturais que desvelam um quadro de valores morais que passa a definir e qualificar como a palavra se torna legítima e, portanto, possivelmente sincera.

Trilling (2014) destacou, portanto, a passagem importante deste processo de mudança dos valores morais atribuídos às declarações pessoais quando indicou claramente que a sinceridade reinou do século XVI até aproximadamente o século XVIII, isto é, quando o código moral da sinceridade, que se apresentava como um vínculo estável 
entre o conhecimento e a expressão de si passou a ser confrontado pelo incômodo do parecer ser, ou seja, da pura aparência como artifício à validação do que era considerado sincero. Esta desestabilização da sinceridade pelo enfrentamento da aparência e recrudescimento da imagem é colocada, principalmente, a partir da filosofia do século XVIII, nas críticas de Rousseau, e onde as vanguardas estéticas também se empenharam em transgredir os códigos de expressão tidos como sinceros e questionados como artifícios das convenções sociais vigentes.

Portanto, neste percurso, se na sinceridade a expressão do eu se dá em acordo com as convenções sociais, na autenticidade, ao contrário, as declarações pessoais se afirmariam pelo confronto entre a expressão do eu - forma original e singular - e o reconhecimento social que apenas valoriza a aparência de ser aquilo que se declarava. É importante ressaltar que esta dicotomia entre sinceridade e autenticidade adquire força na sociedade moderna, pois até este período não havia uma separação entre interior e exterior, público e privado, artifício e realidade. As críticas, sobretudo, em Rousseau, é que começaram a minar este código moral vigente e propor uma alteração profunda no modo de conceber a visibilidade como o espaço do engano e do artifício por excelência.

Bernard Williams (2006), também apresenta uma perspectiva importante acerca desta relação agônica com a autenticidade. A genealogia, método escolhido pelo autor, apresenta a importância de observar um conceito como um discurso que tenta explicar um fenômeno da civilização - como aparece, quais as condições de seu desenvolvimento, como desaparece, ou seja, procura analisar o efeito de um processo histórico não essencialmente constituído por fatos reais apenas, mas que admite também os ficcionais que intervém. Tal como Trilling, Williams também está interessado nas mutações produzidas nos códigos da veracidade, da sinceridade e da autenticidade.

Assim como na compreensão de Trilling, Williams concebe a veracidade (entendida pelo autor como sinceridade) em seu aspecto volitivo e coligado à expressão. $A$ questão que Williams coloca é a de pensar em quais disposições deve estar o locutor - aquele que se declara - para que possa proferir o que considera verdadeiro sabendo que o contexto afeta a natureza da sinceridade. Porém, em sua perspectiva isso não quer dizer dissimulação ou logro, mas que existe um contexto no qual a sinceridade possa ser exercida e tratada como um valor intrínseco ao discurso, aspecto equivalente à parresía em Foucault (2004)'. Esta observação acerca da exigência de um contexto ideal que passa pelo assentimento coletivo seria o que legitimaria a declaração. A cada vez, enfim, que rupturas e confrontos são colocados, a veracidade, sinceridade, refletiriam as alterações incorporadas ao longo deste processo histórico e moral.

Esta visão de Williams (2006) permite notar que há, no pensamento do autor, a importância da partilha dos mesmos códigos e valores sociais que reconhece a sinceridade

\footnotetext{
'Foucault (2004) considera como "técnicas de si" os procedimentos por meio dos quais um indivíduo se apropria de si mesmo, transformando-se em sujeito de suas próprias práticas e construindo a si a partir de uma perspectiva ética que busca distanciar-se das regulações e normatividades, sobretudo, do Estado. Para ele, todo este conjunto de técnicas de meditação, de escrita de si, de dieta, exercícios físicos e espirituais, estão relacionados à parresía, à coragem da verdade, e dizem respeito à capacidade que os indivíduos possuem de efetuar, por si mesmos, um certo número de operações sobre o seu corpo, sua alma, seus pensamentos e condutas de modo a produzir neles uma transformação.
} 
como a virtude do discurso sincero. Pensada nos mesmos parâmetros históricos e morais já indicados por Trilling, Williams também recorre à análise das modificações da sinceridade a partir da concepção de autenticidade forjada na sociedade moderna. Assim, a autenticidade é uma invenção que toca profundamente a sinceridade porque associa os dois valores - sinceridade e autenticidade - à dimensão pessoal investida das convenções morais que viriam lhe emoldurar. Deste modo, um conjunto de necessidades, preocupações, interesses, desejos, enfim, passaria a ser visto como um aspecto a gerir, a administrar, para que estivesse de acordo com a moralidade, a normatização social da vida.

Portanto, as identidades dos sujeitos em um certo grupo, por exemplo, não seriam meras instâncias de decisão individual, mas uma negociação de valores na qual os sujeitos interagem, se reconhecem, se constrangem, enfim, onde movimentam os aspectos que constituem as demandas da autenticidade. Isso significa que a autenticidade não passa por uma decisão interior do indivíduo - o querer ser autêntico - apenas, mas se constitui na conjugação com outros valores, com os aspectos culturais e com os elementos morais e políticos destas interações com os outros.

Era preciso compreender que o sujeito atenderia certa economia da autenticidade por um esforço individual, pela busca de uma equivalência entre sua vida interior e a vida social. Tanto Trilling, quanto Williams entendem a autenticidade como um forte apelo à dimensão social e aos acordos (ou desacordos) que se efetivavam nas interações.

Ao prolongar esta discussão é possível observar atualmente o quanto as exigências sociais que atuam sobre a vida individual se intensificaram. A "busca por ser pleno e sincero" já não se faz pelo exercício de tentar um equilíbrio entre a vida interior do sujeito e a vida social, ou seja, pela oikonomia, mas se impõe como uma força normativa exterior que constrange o sujeito ao puro exercício da gestão e autocontrole.

O caráter dinâmico e de negociação entre as duas esferas, da subjetividade e da sociabilidade, comparece muito mais determinada pela replicação dos códigos que regem condutas e convenções sociais do que por um processo de ajuste, tal qual indicava os autores, no período moderno. Se pudermos colocar em termos comparativos, "ser autêntico" em contexto moderno era um processo de enfrentamento - consigo mesmo e com os outros - cuja dinâmica pretendia o ajuste dos âmbitos interior e exterior, do privado e do público. Atualmente, a busca pelo "ser autêntico" se apresenta inflacionada e hiper-dimensiona a vida exterior e da aparência como determinante do que o sujeito "deve ser" conduzindo-o à desativação dos enfrentamentos e ajustes e consolidando a repetição como recurso da vida interior e subjetiva. A autenticidade como um valor, na visão dos autores, se desvincularia dos aspectos da sinceridade ou da veracidade como aspectos produtivos e das declarações do eu para que a mera repetição do exterior (o social) seja o melhor recurso interior para atingir o reconhecimento social.

Colocada esta tensão central entre sinceridade e autenticidade para legitimação das declarações pessoais aceitáveis em uma determinada sociedade, observa-se que há uma inegável ampliação da concepção teórica e conceitual da escrita autobiográfica nos casos trazidos aqui, que é pensada muito mais como espaço das efetivações de uma heterogeneidade constitutiva do eu, do que como extensão de um gênero literário 
canônico (Arfuch, 2010), e que se aproxima do modo como abordamos os materiais com os quais lidamos na pesquisa.

Nas declarações postadas pelas vítimas emergem dois pontos correlatos desta discussão sobre sinceridade e autenticidade. O primeiro indica que o registro imediato e o compartilhamento das situações vividas e contadas assumem um papel importante neste processo da constituição de uma subjetividade do eu exteriorizada, não apenas por possibilitar a publicização dos acontecimentos da vida de sujeitos comuns instantaneamente, mas porque também adquire uma função moral na legitimidade de quem fala e se expõe. É a própria vítima que se apresenta e reivindica a palavra, pois é ela quem encarna a instância moral e política de suas dores e vivências singulares.

Portanto, tem-se aqui uma construção do lugar de fala do sujeito - o "eu narrador" - que, consciente de seu status e da projeção que pode alcançar, se põe como agente qualificado das dores reais e legítimas que vivencia, ou seja, como autêntico portador de uma experiência originária capaz de mostrar a verdade das coisas que merece ser compartilhada. O segundo ponto se refere ao modo como aquele que se declara vítima organiza a exposição destes materiais que são exibidos e expostos em um ambiente como o das redes sociais, pautado pela centralidade da imagem e aparência.

\section{O VALOR CONVERSACIONAL EM SELFIES DE VÍTIMAS DE VIOLÊNCIA}

André Gunthert (2015) ressalta que as novas relações que se colocam entre produção e distribuição de imagens em nossa sociedade se redefiniram junto com o desenvolvimento dos dispositivos tecnológicos e informacionais. Com as imagens, em particular, as plataformas de produção e compartilhamento, tais como Flickr, Youtube, desde início dos anos 2000, mostraram que a economia das imagens se concentrava na autogestão dos usuários, e não na produção especializada de conteúdos e instituições.

A expansão do mercado de aparelhos portáteis conectados à internet apenas reforçou a multiplicação das diversas plataformas orientadas para o uso do grande público (Gunthert, 2015, p. 80). Os sites de redes sociais, por extensão, investem na simplificação das operações pelos usuários e se consolidam como os novos meios privilegiados da comunicação interpessoal. Neste contexto, segundo o autor, as imagens do cotidiano assumem uma posição de destaque social sem precedente:

muito mais que as obras originais, os instrumentos interativos criaram mecanismos culturais inéditos. A abertura da publicação a uma miríade de interesses particulares obteve como resultado a formação de outro espaço documentário de uma riqueza e diversidade sem precedentes. A igualdade e a reciprocidade da interação instituiu a conversação no modelo de produção cultural. Deste modo, a difusão viral estabeleceu a apropriação como a principal condição das circulações culturais. (Gunthert, 2015, p. 99)

Nas imagens que compõem o corpus desta pesquisa, os sujeitos se declaram vítimas a partir das histórias pessoais de violência que compartilham e dos autorretratos, 
selfies, que são necessários para conferir um rosto, uma identidade, enfim, validar a biografia, a todos os relatos de dor e sofrimento que são veiculados pelos sites de redes sociais. Tornado como um recurso exemplar, inspirador, como de alguém que tem a coragem de se mostrar e contar sua vivência, inúmeras selfies se multiplicam cotidianamente.

Em outubro de 2015, a campanha internacional Creating Consent Culture iniciou uma de suas ações intitulada "Stop rape. Educate". Foi lançada uma página na internet para divulgar suas atividades e auxiliar na difusão de informações sobre a violência sexual e de gênero. Junto com o website, a campanha criou também perfis nos sites de redes sociais Facebook, Twitter e Instagram para atualizações gerais. A hashtag era usada para registrar e divulgar fotografias e vídeos das ações durante as diversas viagens e visitas. No entanto, no dia 21 de novembro de 2015, a jovem Amber Amour, sofre violência sexual e publica, em seu perfil do Instagram, e também no perfil da campanha através do uso da hashtag, o relato da agressão junto com duas fotografias tiradas pouco depois do ocorrido.

Em um autorretrato pode-se encarar seu rosto choroso e assustado, noutra foto ela aparece ainda no leito do hospital enquanto aguardava a realização do exame comprovativo da violência. $\mathrm{Na}$ imagem é possível ver parte das pernas cobertas com o lençol do hospital, de cima para baixo, como uma perspectiva em primeira pessoa. A visualização das pernas, em uma posição que se equivale ao olhar da jovem sobre os membros inferiores de seu corpo, é apresentada pela ironia da própria Amber: "minha visão do kit de estupro", diz.

O plano em primeira pessoa elaborado pela fotografia das pernas envolvidas no lençol do hospital da jovem prestes a fazer um exame verificador dos vestígios do estupro emula a experiência de se ver como Amber, em uma cena circunstanciada pela intimidade e pela dor. Deste modo, cada usuário da rede social poderia, pelo olhar, ocupar o lugar daquele corpo violado. Vinculados à hashtag podem-se comungar os múltiplos olhares do corpo-imagem da jovem Amber. Encorajados e inspirados pela postagem outros jovens publicam, pela mesma hashtag, outros autorretratos associados aos breves relatos de suas experiências violentas.

Em um exemplar, no dia 15 de janeiro de 2016, uma jovem posta uma selfie despida, em frente ao espelho de um banheiro, e destaca, em letras maiúsculas e negrito:

eu não silenciarei minha agressão sexual. Inspirada por Amber, a ativista, eu declaro que tinha 18 anos, tinha saído poucas vezes e tive uma experiência muito limitada com garotos. Eu nunca tive um namorado, quero dizer, eu nunca fui beijada. Então, quando este garoto mais velho e alto, no clube, prestou atenção em mim eu fiquei muito feliz.

A jovem prossegue e conta que encontrou o rapaz em um churrasco na casa de amigos em um sábado. Depois de algum tempo conversando, o rapaz a conduziu a um quarto, onde tentou despi-la. No entanto, ela diz em seu relato que tentou parar o rapaz e lhe disse que não se sentia preparada, mas foi jogada no chão enquanto ele retirava o calção. 
Depois de contar os detalhes da agressão, a jovem finaliza sua história declarando o quanto se sentiu "culpada, confusa e enojada durante dias. (...) Este foi o primeiro cara com quem tive esta experiência íntima que me marcou durante anos. É importante para mim contar minha história porque eu sobrevivi e você também pode". Reiterando o caráter exemplar da postagem justificada pelo dever de se revelar, de se expor e contar sua experiência em nome da verdade, ao final, a jovem também indexa sua foto na hashtag da campanha.

No dia 20 de março de 2016 um rapaz faz o mesmo e publica uma selfie na hashtag onde aparece segurando uma espécie de cartaz que reproduz a fala do seu violador: "vamos, primo, é divertido. (...) é só um jogo". Assim como os demais, ele se apresenta em imagem e conta uma parte da agressão vivida.

Ao refletir acerca da expansão massiva de selfies nos mais diversos perfis que compõem as redes sociais, André Gunthert (2015) indica que é importante compreender o rápido desenvolvimento do autorretrato instantâneo, não pelo acesso popular aos dispositivos tecnológicos apenas, mas a partir do gesto de produzir uma imagem que busca instaurar uma forma particular de conversação. Convocados a participar da situação precisa que a foto postada oferece, os demais usuários ultrapassariam certo limite convencional da representação e seriam provocados a participar, de algum modo, daquela situação exposta e oferecida.

Tais imagens, segundo Gunthert (2016), produzem uma mensagem principal que se caracteriza pela situação intersubjetiva que se instaura entre seus espaços, ou seja, dentro e fora da imagem, assim como pelos limites temporais de passado e presente da situação compartilhada, em geral, dados no momento imediato ou pelos vestígios recentes trazidos pelas fotos. "A fotografia executada em um momento preciso não é apenas uma imagem de si, nem apenas uma imagem do local, mas precisamente o registro visual desta articulação efêmera; a relação do ator e a situação, inscrita na imagem" (Gunthert, 2015, p. 154).

Este tipo de conversação vernacular, prosaica, predominante nas selfies que circulam em hashtags e sites de redes sociais busca promover justamente a interação e a repercussão entre os demais usuários. Guiado por estes aspectos, convém ao sujeito autor-personagem, a vítima, fornecer, através de suas imagens, material que provoque alguma forma de réplica que incite uma conversação:

é jogando com as incertezas do enquadramento, dos registros visuais de um manejo ou do amadorismo do ponto de vista, que a selfie apresenta um conjunto de falhas visíveis que são rapidamente consideradas como a assinatura do gênero. Estas falhas que as distanciam das regras de composição do retrato, e que lhes conferem o frescor e a originalidade, foram compreendidas como manifestações de autenticidade. Contrariamente à lei de ferro da representação que, desde a caverna de Platão repousa sobre a dissimulação do dispositivo, que a exibição do caráter autoproduzido da imagem se tornou uma garantia de espontaneidade e fidedignidade. (Gunthert, 201, p. 160) 
A proposição de interação dada em uma selfie se torna atraente na medida em que comporta tanto uma dimensão pessoal quanto fornece aos seus interlocutores materiais sugestivos da situação particular referenciada capazes de instaurar alguma forma de conversação, relação ou engajamento com os demais usuários. Neste texto, observamos que os autorretratos veiculadas pela hashtag assumem uma função importante tanto para adensar o valor de sinceridade de suas declarações, como discutido no tópico anterior, quanto para instaurar as linhas conversacionais com os demais usuários, para fazer apelo à adesão de sua história vivida e exposta, recurso tão necessário, quanto típico deste tipo de material que movimenta o ambiente online.

Sob esta perspectiva é possível notar que as práticas de exposição do sujeito envolvidas nestas formas de comunicação em rede - a um só tempo midiatizada, tecnológica e institucional - só adquirem certa relevância na reordenação narrativa de uma experiência violenta, como da agressão sexual, que passa do recato da dor íntima à exposição da denúncia e declaração pessoal, por conta de certa política do olhar que se institui atualmente. Neste contexto, fazer-se imagem, contar sua história, compartilhar, adensa a auto-exposição como um valor fundamental no manejo destes diversos recursos tecnológicos disponíveis.

Segundo Heinich (2012), a visibilidade se tornou um capital social dos mais importantes na constituição dos sujeitos no tecido social hoje:

ele não é uma simples metáfora do capital econômico: é o capital econômico que precisa considera-lo como um tipo particular de capital, entre outros possíveis, no vasto conjunto de recursos que permitem a um indivíduo ocupar um lugar na hierarquia social. (Heinich, 2012, p. 51)

Simbólico e peculiar, o capital de visibilidade é constitutivamente circular e autoprodutivo e participa ativamente no ambiente marcado pela gestão da autoimagem como ocorre nas redes sociais.

\section{Considerações Finais}

É preciso considerar que, no contexto das sociedades atuais, os sujeitos se apropriam das ferramentas e meios tecnológicos de maneiras diversas. Mas para além do manejo técnico há uma dimensão simbólica imbricada aos usos como o imaginário, as crenças, as emoções, valores, enfim, manifestações de ordem subjetiva, bem como social.

O cotidiano dos sujeitos hoje compreende tanto a apropriação quanto a capilarização dos meios e dispositivos técnicos que muito possibilitam discussões e abordagens sobre comportamentos, tendências e orientações sociais e culturais. Uma vez considerados os refluxos entre as dimensões online e offline, uma investigação interpretativa destes materiais pode contribuir significativamente sobre a percepção e orientação dos sujeitos e grupos acerca de inúmeros temas e fatos, mas não podem ser tomados como verdades únicas que traduzem ou determinam os valores, ações ou as crenças de qualquer grupo ou comunidade, mas sim seus indícios e suas marcas. 
A forma de exposição destas experiências, bem como a configuração de lugares para a apresentação destas vítimas, interessam sob uma dimensão específica dos relatos, do gesto de "relatar a si mesmo" (Butler, 2015; Rago, 2013). A produção de testemunhos ${ }^{2}$ fundamentados em um valor de verdade do sujeito, que sofre e declara sua própria experiência da dor, revela, ao mesmo tempo, uma dimensão social e cultural da vítima que tem investido em engajamentos e interações moduladas em rede.

A reflexão trazida neste texto apenas buscou aprofundar uma perspectiva que explora o lugar da declaração pessoal, da enunciação da vítima, pelo adensamento da noção do eu-sujeito como expressão privilegiada da visibilidade da vítima em um contexto como o das redes sociais. Se a vítima hoje reivindica uma legitimidade por ter tido uma experiência dolorosa, a visibilidade associada neste processo de auto declaração e afirmação é o elemento que lhe autentica, que arremata e carimba sua efetividade.

A declaração pessoal na exposição da história vivida e na revelação biográfica da vítima são necessárias à autenticação que passa também pela aceitação e reconhecimento do grupo, dos demais usuários. Daí que se torna imperativo reiterar o fato vivido no compartilhamento. Há um valor diferenciado que entra em jogo neste processo, e não é aquele da performance entendida como uma forma de elaboração de uma mis-en-scène, mas de uma apresentação direta, imediata e instantânea de uma presumida vida sincera e sem filtro.

\section{FinANCIAMENTo}

Bolsa de Estágio Pós-Doutoral. Coordenação de Aperfeiçoamento de Pessoal de Nível Superior. Ministério da Educação. Brasil

\section{REFERÊNCIAS BIBLIOGRÁFICAS}

Arfuch, L. (2010). O espaço biográfico. Dilemas da subjetividade contemporânea. Rio de Janeira: Ed. UERJ.

Butler, J. (2015). Relatar a si mesmo. Belo Horizonte: Autêntica.

Foucault, M. (2001). Le sujet et le pouvoir. In M. Foucault, Dits et Écrits II, 1976-1988 (pp. 1041-1062). Paris: Gallimard.

Foucault, M. (2004). A ética do cuidado de si como prática da liberdade. In M. Foucault, Ética, Sexualidade e Política (pp. 264-287). Rio de Janeiro: Forense Universitária.

Gunthert, A. (2015). L'image partagée. La photographie numérique. Paris: Éditions Textuel.

Heinich, N. (2012). De la visibilité. Excellence et singularité en régime médiatique. Paris: Gallimard.

Rago, M. (2013). A aventura de contar-se: feminismos, escrita de si e invenções da subjetividade. Campinas: Editora Unicamp.

Taylor, C. (1997). As fontes do self: a construção da identidade moderna. São Paulo: Loyola.

${ }^{2}$ Este aspecto apenas mencionado neste texto foi apresentado e melhor desenvolvido em outros textos publicados relativos à pesquisa. 
Trilling, L. (2014). Sinceridade e autenticidade: a vida em sociedade e a afirmação do eu. São Paulo: É Realizações Editora.

Williams, B. (2006). Vérité et véracité. Paris: Gallimard.

\section{Nota BiográficA}

Angie Gomes Biondi é doutora em Comunicação Social pela Universidade Federal de Minas Gerais. Professora Adjunta do Programa de Pós-Graduação em Comunicação e Linguagens da Universidade Tuiuti do Paraná, Brasil. Pesquisa Pós-doutoral realizada na Université du Québec à Montréal, Canadá.

E-mail: angiebiondina@gmail.com

Universidade Tuiuti do Paraná. Rua Sydnei Santos Rangel, 238. Santo Inácio, Curitiba/PR, CEP: 82010-330, Brasil

Submetido: 01/03/2017

Aceite: $30 / 04 / 2017$ 